\title{
Lower PRDM2 expression is associated with dopamine-agonist resistance and tumor recurrence in prolactinomas
}

\author{
Hua Gao ${ }^{1 \dagger}$, Fei Wang ${ }^{2 \dagger}$, Xiaolei Lan ${ }^{1,3}$, Chuzhong Li ${ }^{1}$, Jie Feng ${ }^{1}$, Jiwei Bai ${ }^{4}$, Lei Cao ${ }^{1}$, Songbai Gui ${ }^{4}$, \\ Lichuan Hong ${ }^{5}$ and Yazhuo Zhang ${ }^{1 *}$
}

\begin{abstract}
Background: Dopamine agonists (DAs) are the first-line treatment for prolactinomas, which account for 25-30\% of functioning pituitary adenomas, and bromocriptine (BRC) is the only commercially available DAs in China. However, tumors are resistant to therapy in $5-18 \%$ of patients.

Methods: The exomes of six responsive prolactinomas and six resistant prolactinomas were analyzed by whole-exome sequencing.

Results: Using stringent variant calling and filtering parameters, ten somatic variants that were mainly associated with DNA repair or protein metabolic processes were identified. New resistant variants were identified in multiple genes including PRDM2, PRG4, MUC4, DSPP, DPCR1, RP1L1, MX2, POTEF, C10rf170, and KRTAP10-3. The expression of these genes was then quantified by real-time reverse-transcription PCR (RT-qPCR) in 12 prolactinomas and 3 normal pituitary glands. The mRNA levels of PRDM2 were approximately five-fold lower in resistant prolactinomas than in responsive tumors $(p<0.05)$. PRDM2 protein levels were lower in resistant prolactinomas than in responsive tumors, as determined by Western blotting and immunohistochemical analysis $(p<0.05)$. Overexpression of PRDM2 upregulated dopamine receptor D2 (D2DR) and inhibited the phosphorylation of ERK1/2 in MMQ cells. PRDM2 showed a synergistic effect with BRC on the inhibition of prolactin (PRL) secretion and MMQ cell viability, and low PRDM2 expression was associated with tumor recurrence.
\end{abstract}

Conclusions: PRDM2 downregulation may play a role in dopamine-agonist resistance and tumor recurrence in prolactinomas.

Keywords: Prolactinomas, Whole-exome sequencing, Dopamine agonists, Drug resistance, PRDM2

\section{Background}

Prolactinomas account for $25-30 \%$ of functioning pituitary tumors, with an estimated prevalence of 100 cases per 100,000 individuals [1-3]. Pharmacological intervention is the first-line treatment and involves the use of dopamine agonists (DAs) to reduce tumor size and prolactin level. $\mathrm{BRC}$, the oldest drug for the medical treatment of prolactinomas, was introduced into clinical practice approximately 30 years ago $[1,4]$ and is the only commercially available DAs in China. In $80-90 \%$ of patients with

\footnotetext{
* Correspondence: zyz2004520@yeah.net

${ }^{\dagger}$ Equal contributors

'Beijing Neurosurgical Institute, Capital Medical University, Beijing, China Full list of author information is available at the end of the article
}

microprolactinomas and $70 \%$ of individuals with macroprolactinomas, BRC treatment controls hyperprolactinemia, restoring gonadal function and reducing tumor size. Side effects of BRC include nausea, dizziness (orthostatic hypotension), nasal stuffiness, difficulty concentrating, depression, psychosis, and peripheral vasospasm and so on [1].

Resistance to BRC, defined as the absence of normalization of prolactin (PRL) levels despite a $15 \mathrm{mg}$ daily dose of BRC during at least 3 months, has been observed in $5-18 \%$ of prolactinomas according to the literature $[3,5]$. The mechanisms underlying BRC resistance of prolactinomas are not fully understood, although such resistance to BRC correlates with reduced binding to the D2 
receptor subtype of dopamine, the major PRL inhibiting factor. Resistance to BRC therapy may involve defects in D2 dopamine receptor expression and possibly its posttranscriptional splicing [6,7]. The ability to predict the degree and extent of BRC resistance would enable the design of personalized treatment regimens. Lack of therapeutic response to BRC may be an indication for surgery or radiation therapy. In the present study, we used stringent variant calling and filtering parameters and identified 10 somatic mutations mainly associated with DNA repair or the protein metabolic process by using whole-exome sequencing in combination with homozygosity mapping in a comparative analysis of BRC-responsive and BRCresistant prolactinomas. We describe a new candidate gene associated with BRC resistance in prolactinomas, PRDM2, and show that the protein and mRNA levels of PRDM2 are lower in BRC-resistant prolactinomas than in BRC-responsive prolactinomas.

\section{Methods}

\section{Patients and specimens}

Samples from six BRC-responsive prolactinomas and six BRC-resistant prolactinomas were obtained from the biobank of Beijing Neurosurgical Institute. And these patients underwent endoscopic trans-sphenoidal surgery between December 2008 and January 2011 at Tiantan Hospital, Beijing, China. Informed consent was obtained from patients using protocols approved by IRB of Beijing Tiantan Hospital Affiliated to Capital Medical University (KY2013015-2). Pituitary prolactinomas which were obtained from 12 patients ( 8 men and 4 women, mean age 37.4 years,range 15-63 years) without a family history of endocrine neoplasia were characterized on presurgical clinical and biochemical findings and morphological and immunohistochemical analysis of removed tissue samples (Table 1).
Resistant tumors were defined as those from patients whose serum PRL levels remained abnormally high after at least 3 months of treatment with a daily dose of at least $15 \mathrm{mg} \mathrm{BRC}(1 ; 3)$. The tumors did not have features of atypia, and they constituted the discovery set of tumors for exome capture and DNA sequence analysis. Additional twenty-four pituitary prolactinomas, histologically confirmed, were obtained from 8 women and 16 men (mean age 61 years, range 17-71 years), and these constituted the validation set (Table 2).

\section{Exome capture, DNA sequencing, and bioinformatics analysis}

Total DNA was extracted from prolactinomas using the QIAamp DNA Mini Kit (QIAGEN, Hilden, Germany). An aliquot containing $5 \mu \mathrm{g}$ of genomic DNA was purified and quantified from each specimen. Exome enrichment was performed by using an ABI SOLiD optimized SureSelect Human All Exon kit (Agilent, Santa Clara, CA, USA), which included the exonic sequences of $\sim 18,000$ genes, covering a total of $37 \mathrm{Mb}$ of genomic sequences. The enriched exome libraries were then amplified by emulsion PCR(ePCR), according to the manufacturer's instructions (Life Technologies, Carlsbad, CA, USA), based on a library concentration of $0.5 \mathrm{pM}$. The PCR products were then sequenced on a SOLiD5500 sequencer (Life Technologies); one quad of a SOLiD sequencing slide was required for each sample.

Color-space reads were mapped to the hg19 reference human genome using SOLiDBioScope software (Life Technologies), which is suitable for a repetitive mapping approach. Single-nucleotide polymorphisms (SNPs) were then called using the diBayes algorithm with conservative default call stringency [8]. We excluded known SNPs available from the Single Nucleotide Polymorphism Database

Table 1 Patients classification according to their response to BRC

\begin{tabular}{|c|c|c|c|c|c|c|c|}
\hline \multirow{2}{*}{$\begin{array}{l}\text { Patient } \\
\text { number }\end{array}$} & \multicolumn{3}{|c|}{ Serum PRL levels $(\mu \mathrm{g} / \mathrm{ml})$} & \multirow[t]{2}{*}{ Tumor size(cm) } & \multirow{2}{*}{$\begin{array}{l}\text { Higher BRC } \\
\text { dose (mg/day) }\end{array}$} & \multirow{2}{*}{$\begin{array}{l}\text { Months with } \\
\text { higher BRC dose }\end{array}$} & \multirow[t]{2}{*}{ Classification } \\
\hline & Before BRC & With BRC & Normal? & & & & \\
\hline 1 & 928 & 3.9 & YES & 2 & 5 & 6 & Responsive \\
\hline 2 & 4843 & 15 & YES & 2.5 & 2.5 & 10 & Responsive \\
\hline 3 & 122.3 & 3.18 & YES & 1.8 & 2.5 & 3 & Responsive \\
\hline 4 & 899 & 7.6 & YES & 4.5 & 7.5 & 6 & Responsive \\
\hline 5 & 3117 & 9.2 & YES & 2.5 & 7.5 & 3 & Responsive \\
\hline 6 & 3830 & 15.5 & YES & 2 & 5 & 8 & Responsive \\
\hline 7 & 975 & 165 & NO & 3.5 & 15 & 4 & Resistant \\
\hline 8 & $>6000$ & 268 & NO & 3 & 15 & 5 & Resistant \\
\hline 9 & 182 & 83.2 & NO & 2 & 15 & 5 & Resistant \\
\hline 10 & $>6000$ & 68.2 & NO & 2.5 & 15 & 6 & Resistant \\
\hline 11 & 2899 & 128.6 & NO & 5 & 15 & 24 & Resistant \\
\hline 12 & 168 & 150 & NO & 0.8 & 15 & 6 & Resistant \\
\hline
\end{tabular}


Table 2 Relationship between PRDM2 mRNA levels in prolactinomas and various clinical parameters

\begin{tabular}{|c|c|c|c|c|}
\hline \multirow[b]{2}{*}{ Feature } & \multicolumn{2}{|c|}{ PRDM2 mRNA levels } & \multirow[b]{2}{*}{ Chi-square } & \multirow[b]{2}{*}{$p$-Value } \\
\hline & High* & Low & & \\
\hline All cases & 12 & 12 & & \\
\hline \multicolumn{5}{|l|}{ Patient's age } \\
\hline$\geq 50$ & 5 & 6 & 0.168 & 0.682 \\
\hline$<50$ & 7 & 6 & & \\
\hline \multicolumn{5}{|l|}{ Patient's gender } \\
\hline Male & 9 & 7 & 0.756 & 0.385 \\
\hline Female & 3 & 5 & & \\
\hline \multicolumn{5}{|c|}{ Serum PRL levels } \\
\hline$\geq 435 \mu \mathrm{g} / \mathrm{ml}$ ** & 4 & 5 & 0.178 & 0.673 \\
\hline$<435 \mu \mathrm{g} / \mathrm{ml}$ & 8 & 7 & & \\
\hline \multicolumn{5}{|l|}{ Tumor size } \\
\hline$\geq 2 \mathrm{~cm}$ & 5 & 7 & 0.670 & 0.413 \\
\hline$<2 \mathrm{~cm}$ & 7 & 5 & & \\
\hline \multicolumn{5}{|l|}{ Recurrence ${ }^{* * *}$} \\
\hline Yes & 4 & 10 & 6.511 & 0.011 \\
\hline No & 8 & 2 & & \\
\hline \multicolumn{5}{|c|}{ Resistance to $\mathrm{BRC}^{* * * *}$} \\
\hline & 4 & 9 & 4.332 & 0.037 \\
\hline & 8 & 3 & & \\
\hline
\end{tabular}

*The median expression level was used as the cutoff. Low PRDM2 mRNA levels were defined as values below the 50th percentile of the 12 patients; values at or above the 50th percentile were classified as high levels.

**The median serum PRL level was used as the cutoff: $435 \mu \mathrm{g} / \mathrm{ml}$. Low serum PRL levels were defined as values below the 50th percentile of the 12 patients; values at or above the 50th percentile were classified as high levels. ***Recurrence was defined as the discovery of an elevated PRL level at any time in the postoperative surveillance period after an initial remission.

****Resistant tumors to BRC were defined as those from patients whose serum PRL levels remained abnormally high after at least 3 months of treatment with a daily dose of $15 \mathrm{mg} \mathrm{BRC}$.
(dbSNP) v130, maintained by the National Center for Biotechnology Information (NCBI).

\section{RNA extraction and real-time reverse-transcription quantitive PCR (RT-qPCR)}

Total RNA was extracted from prolactinomas ( 50 mg) stored in liquid nitrogen using the TRIzol Reagent (Life Technologies). The primers used in real-time reversetranscription PCR (RT-qPCR) are listed in (Table 3). RTqPCR was performed as described previously [3], using Applied Bio-systems 7500 Fast System (Life Technologies). The fold-change in differential expression for each gene was calculated using the comparative $C_{\mathrm{T}}$ method (also known as the $2^{-\Delta \Delta C T}$ method) as previously described [9].

\section{Plasmid constructs}

The human PRDM2 cDNA was obtained by reverse transcriptase-polymerase chain reaction from human brain RNA with primers (forward 5'-TCTGCTGTTGACAAG ACCC-3', reverse 5'-GCATCAATGCACATCCATC -3') designed according to the prdm2 sequence published in GenBank (NM_001135610.1). The cDNA was directionally cloned into the pCMV6 plasmid (Invitrogen). The orientation of the WT cDNA was verified by DNA sequencing.

\section{Assessment of cell viability}

To evaluate the effect of PRDM2 on cell viability, $1 \times 10^{4}$ MMQ cells were transfected with PRDM2 for $24 \mathrm{~h}, 48 \mathrm{~h}$ and $72 \mathrm{~h}$ in 96 -well plates. A total of $20 \mu \mathrm{l} \mathrm{of} 5 \mathrm{mg} / \mathrm{ml} \mathrm{3-}$ (4,5-dimethylthiazol-2-yl)-2,5-diphenyl tetrazolium (MTT) was added into each well to continue the culture for another $4 \mathrm{~h}$. Culture medium was discarded and dimethyl sulfoxide was added at $100 \mu \mathrm{l} /$ well. The mixture was shaken for $10 \mathrm{~min}$ at a constant temperature of $37 \mathrm{C}$ before absorbance measurement.

\section{Concentration of cell PRL secretion assays using ELISA}

To evaluate the effect of PRDM2 on PRL secretion, $1 \times$ $10^{6}$ MMQ cells were transfected with PRDM2 $(1 \mu \mathrm{g})$ for

Table 3 Primers used for RT-qPCR analysis of the expression of 10 variant genes

\begin{tabular}{lll}
\hline Gene & Forward primer & Reverse primer \\
\hline C10rf170 & 5'-CACCCTGCGTTCTTCTGG-3' & 5'-TGCCCATCCCCTCTTTG-3' \\
DPCR1 & 5'-AGTGCTGCCTCCTCTTCCTTCTA-3' & 5'-GGGAGCTCTGGAGGTCTTTGTC-3' \\
DSPP & 5'-GCATTTGGCAGTAGCATGG-3' & 5'-CTGACACATTTGATCTTGCTAGGAG-3' \\
KRTAP10-3 & 5'-AGCCAGCTTGCTGCACAT-3' & 5'-TGAAGAGGAAGCCCCAGAG-3' \\
MUC4 & 5'-GCCAACTTCACGCTCAGAGAC-3' & 5'-TCTCCAGAGTGAATGGCTCCAG-3' \\
MX2 & 5'-GCCAGGTGGAGAAAGAGATACACAA-3' & 5'-AGGTCAATGATGGTCAGGTCTGG-3' \\
POTEF & 5'-CTGCATGTGGCGTGACTCTG-3' & 5'-CGGCATGGAATCAACCTCAA-3' \\
PRDM2 & 5'-AGCAGCTGCGATTGAGGA-3' & 5'-CAGAGGTGAAATCTGGCTCACTT-3' \\
PRG4 & 5'-GGCAGCGCTITCAACAGCTAA-3' & 5'-CCAGGGCACTTCTGTACAGGTTC-3' \\
RP1L1 & 5'-AGAAGCGAGGCTGAAACTTTATCTG-3' & 5'-TCACACTCGGCTTGGTCTTGG-3' \\
\hline
\end{tabular}


$24 \mathrm{~h}$. Addition of BRC (40nM) to test wells and PBS with corresponding solvent added to control wells was followed by culture for $24 \mathrm{~h}$ and centrifugation to collect the supernatant. Then following the directions of the rat PRL ELISA kit manual, the concentrations of PRL were estimated from a standard curve of known PRL concentrations.

Immunohistochemical analysis of prolactinoma specimens The immunohistochemical SABC method was used as described previously [8]. Prolactinoma and pituitary gland specimens were sectioned to a thickness of $5 \mu \mathrm{m}$ in paraffin wax. The sections were subjected to gradient dewaxing, removed to water, treated with fresh $3 \%$ hydrogen peroxide at room temperature for $10 \mathrm{~min}$, and washed with PBS (PH 7.2) 3 times for 5 min each. For microwave repair, the specimens were placed in $0.01 \%$ citric acid ( $\mathrm{pH}$ 6.0), kept warm in a microwave oven (600 W) for $10 \mathrm{~min}$, allowed to cool to room temperature, and washed once with PBS. Antibody repair solution I was added at room temperature for $10 \mathrm{~min}$, and then washed 3 times with PBS for 5 min each time. Primary PRDM2 (RIZ1) antibody was added at a 1:200 dilution and incubated at $4^{\circ} \mathrm{C}$ overnight. The daylight ${ }^{\mathrm{Tm}}$ conjugated affinipure second antibody with fluorescence was added at room temperature for $1 \mathrm{~h}$ followed by 3 washes with PBS for 5 min each time. SABC was added for $20 \mathrm{~min}$ and then washed with adequate PBS. Sections were mounted with Prolong Gold Antifade reagent with 4',6-diamidino-2phenylindole (DAPI) (Invitrogen). Sections were analyzed with a LEICA-TCS-SP5II to estimate the percentage of DAPI-stained cells displaying PRDM2 immunoreactivity.

\section{SDS-PAGE and Western blot analyses}

Prolactinomas and normal pituitary specimens were lysed in TNE buffer (50 mM Tris-HCl, pH 7.4, $150 \mathrm{mM}$ $\mathrm{NaCl}, 1 \mathrm{mM}$ EDTA; all from Sigma-Aldrich) containing $1 \%$ Nonidet P-40 (Calbiochem) with protease and phosphatase inhibitor cocktails (Roche). Total extracts were centrifuged at $12000 \times g$ for $30 \mathrm{~min}$ at $4^{\circ} \mathrm{C}$, and the protein concentration of the supernatant was determined with a BCA protein assay kit (Pierce Biotechnology). For western blot analysis, $40 \mu \mathrm{g}$ of lysate per lane was loaded onto 4$12 \%$ Bis-Tris SDS-PAGE gels, separated electrophoretically, and blotted onto polyvinylidene fluoride (PVDF) membranes. Different blots were incubated with antibodies against D2DR (1:2000, Abcam), p-ERK1/2 (1:1000, CST), PRL (1:1000, Santa-Cruz), T-ERK1/2(1:1000, CST), PRDM2 (1:500, Abcam) and $\beta$-actin (Sigma) followed by secondary antibodies tagged with horseradish peroxidase (Santa Cruz Biotechnology). Blots were visualized by enhanced chemiluminescence, and densitometry was performed with a Versadoc XL imaging apparatus (Bio-Rad). Analysis of $\beta$-actin levels was used as a loading control.

\section{Statistical analysis}

All the statistical analyses were performed using SPSS version 20.0. For comparisons, one-way analyses of variance, chi-squared tests, Wilcoxon rank-sum test and twotailed Student's $t$-tests, were carried out as appropriate. Binary logistic regression was performed to identify independent factors related to prolactinoma recurrence.

\section{Results}

\section{Identification of variant genes by whole-exome} sequencing

The exomes of six BRC-responsive prolactinomas and six BRC-resistant prolactinomas were analyzed by wholeexome sequencing which yielded excellent target region coverage with approximately $71 \%$ of the exome covered to a depth of at least ten-fold between the somatic variant calling algorithm and confirmatory sequencing. Several prioritization steps were taken to decrease the number of genetic variants and to find the potentially pathogenic variants [10]. Approximately $90 \%$ of single-nucleotide variants (SNVs) resulted in missense amino-acid changes, whereas the remaining approximately $10 \%$ were synonymous changes. More than $70 \%$ of the SNVs occurred as C: G-T: A transitions, and less than $30 \%$ were transversions. Using stringent variant calling and filtering parameters, 119 somatic variants were identified in these specimens. A comparison with the NCBI dbSNP, with recently released SNP data from other groups and with in-house SNP data confirmed that $>90 \%$ of the identified variants were previously reported SNPs that did not seem to explain BRC resistance of prolactinomas. Ten variant genes were selected for further study: C1orf170, DPCR1, DSPP, KRTAP10-3, POTEF, MUC4, MX2, PRDM2, PRG4, RP1L1 (Table 4) and the original data were shown in Additional file 1: Table S1.

\begin{tabular}{|c|c|c|}
\hline Gene & GenBank ID & Encoded protein \\
\hline Clorf170 & BC006300 & $\begin{array}{l}\text { Uncharacterized protein, chromosome } \\
1 \text { ORF } 170\end{array}$ \\
\hline$D P C R 1$ & NM_080870 & $\begin{array}{l}\text { Diffuse panbronchiolitis critical region } \\
\text { protein } 1\end{array}$ \\
\hline DSPP & NM_014208 & Dentin sialophosphoprotein \\
\hline KRTAP10-3 & NM_198696 & Keratin associated protein 10-3 \\
\hline POTEF & NM_001099771.2 & POTE ankyrin domain family, member $F$ \\
\hline MUC4 & NM_138297.4 & Mucin 4, cell surface associated \\
\hline$M \times 2$ & NM_002463 & $\begin{array}{l}\text { Myxovirus (influenza virus) resistance } \\
\text { protein } 2\end{array}$ \\
\hline PRDM2 & NM_001007257.2 & $\begin{array}{l}\text { PR domain containing 2, with ZNF } \\
\text { domain }\end{array}$ \\
\hline PRG4 & NM_005807. & $\begin{array}{l}\text { Proteoglycan } 4 \text { (PRG4), transcript } \\
\text { variant A }\end{array}$ \\
\hline$R P 1 L 1$ & NM_178857 & Retinitis pigmentosa 1-like 1 protein \\
\hline
\end{tabular}


Analysis of the expression of variant genes by RT-qPCR We used real time quantitative PCR (RT-qPCR) to test whether BRC resistance in prolactinomas was associated with differences in the expression levels of any of 10 variant genes. Indeed, the mRNA levels of C1orf170, DPCR1, KRTAP10-3, PRDM2 and RP1L1 were 50\% lower in resistant tumors than in responsive tumors. In particular, PRDM2 mRNA levels were approximately five-fold lower in resistant prolactinomas than in the responsive tumors ( $\mathrm{p}<0.05)$. By contrast, the mRNA levels of DSPP, PRG4, $M U C 4, P O T E F$ and $M X 2$ were higher in resistant prolactinomas than in the responsive tumors $(\mathrm{p}>0.05)$. Mean expression levels of the 10 genes are shown in Figure 1 and Table 5 (statistical method: two-tailed Student's t tests).

\section{Identification of candidate driver mutations}

Somatic mutations in genes previously associated with pituitary tumorigenesis including $A I P, B M P-4, C D K N 1 B$, CDKN2A, CDKN2C, Cyclin D1, D2R, GADD45G, Gsp, MEG3a, MEN1, p53, Pdt-FGFR4, PKC, PRKAR1A, PTTG, RAS, SSTR2/SSTR5, WIF-1 and ZAC1[8,11] were not detected. To identify putative driver mutations, further analysis of each of the somatic variants was performed. We hypothesized that putative driver mutations would typically: 1) have a deleterious effect on protein function; 2) be present at sufficient allele frequency to represent likely heterozygous or homozygous changes; and 3) be involved in biological processes relevant to tumorigenesis [12].

Using these criteria, PRDM2 (retinoblastoma interacting zinc-finger protein, RIZ) was selected for further evaluation. The PRDM2 gene was isolated in a functional screening for $\mathrm{Rb}$-binding proteins. The PRDM2 gene is one of the candidate tumor suppressor genes on chromosome 1p. Moreover, inactivation of the PRDM2 gene by promoter hypermethylation has been reported in breast, liver, and gastric carcinomas [13,14]. To investigate the potential role of PRDM2 in BRC resistance, we measured the level of PRDM2 expression by western blotting and immunohistochemistry in six resistant prolactinomas, six sensitive prolactinomas and three normal pituitary glands. The PRDM2 protein level in the BRC-resistant group was approximately $24.6 \pm 5.2 \%$ of that in the normal pituitary gland ( $\mathrm{p}<0.01$ ); however, the PRDM2 protein level in the BRC-responsive group was $78.3 \pm 6.1 \%$ of that in the normal pituitary gland $(\mathrm{p}<0.05)$ (Figure 2$)$. PRDM2 protein levels were obviously lower in resistant prolactinomas than in the responsive tumors $(\mathrm{p}<0.05)$. Confocal images showed that the number of PRDM2-positive puncta in BRC-resistant prolactinomas was lower than that of the normal pituitary and sensitive prolactinomas (Figure 3). And the levels of PRDM2 mRNA in BRC-resistant prolactinomas were about five lower than in the responsive tumors $(\mathrm{p}<0.05)$, and about eight fold lower than in normal pituitary glands (Figure 4).

\section{PRDM2 showed a synergistic effect with BRC on the inhibition of PRL secretion and MMQ cell viability}

$\mathrm{BRC}$ is derived by semisynthesis and has D2 receptor agonist and D1 receptor antagonist properties. We found that overexpression of PRDM2 could increase the D2R level and PRL level of MMQ cells by Western blot (Figure 5A). In additional, PRDM2 could reduce the phosphorylation of

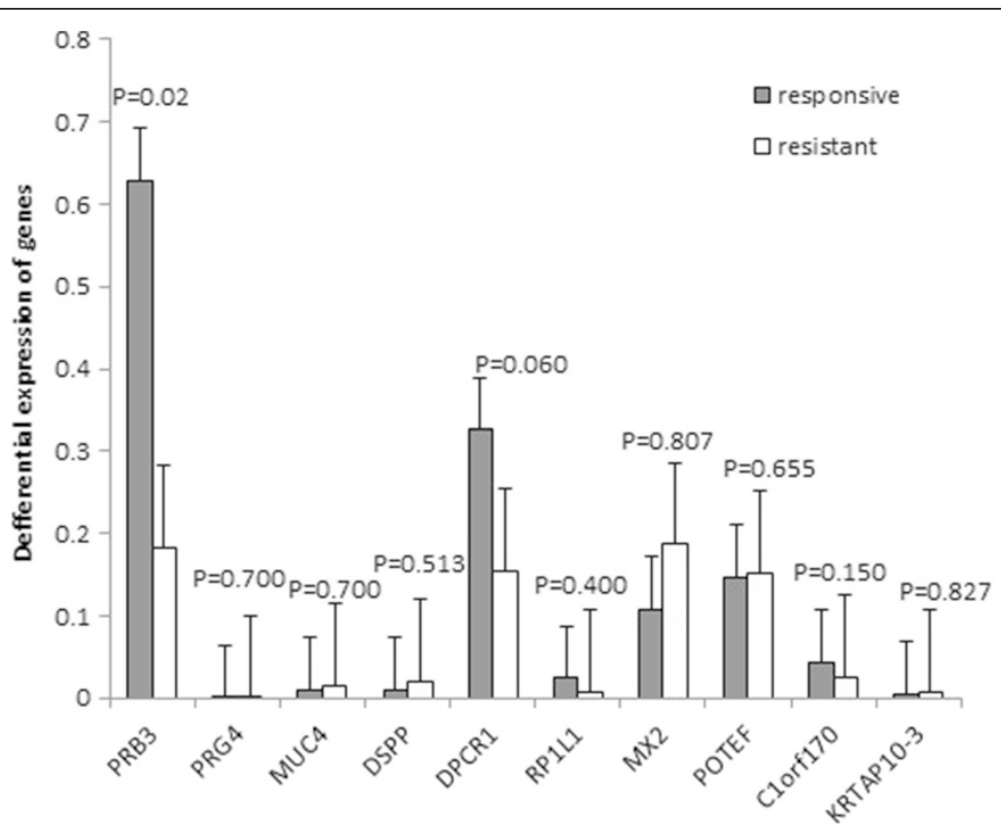

Figure 1 RT-qPCR analysis of 10 variant genes in BRC-responsive and BRC-resistant prolactinomas. Only the differential expression of PRDM2 was statistically significant. 
Table 5 Differential expression folds of genes

\begin{tabular}{llll}
\hline & Responsive & Resistant & p value \\
\hline PRDM2 & 0.260138247 & 0.05833261 & 0.020 \\
PRG4 & 0.000109963 & 0.000281276 & 0.700 \\
MUC4 & 0.010466577 & 0.015666494 & 0.700 \\
DSPP & 0.010298289 & 0.021137023 & 0.513 \\
DPCR1 & 0.3257084 & 0.154926532 & 0.060 \\
RP1L1 & 0.023944092 & 0.006293673 & 0.400 \\
MX2 & 0.108311332 & 0.18653675 & 0.807 \\
POTEF & 0.146750534 & 0.150689894 & 0.655 \\
C1Orf170 & 0.043853399 & 0.024682049 & 0.150 \\
KRTAP10-3 & 0.003738342 & 0.006845497 & 0.827 \\
\hline
\end{tabular}

ERK1/2 (Figure 5A) and reduce the cell viability of MMQ cells (Figure $5 \mathrm{~B}$ ).

To evaluate the effect of PRDM2 on PRL secretion, $1 \times$ $10^{6}$ MMQ cells were transfected with PRDM2 $(1 \mu \mathrm{g})$ for $24 \mathrm{~h}$. Another $24 \mathrm{~h}$ was cultured with BRC (40nM) to test wells and isometric DMSO as control wells. BRC could inhibit the PRL secretion and MMQ cell viability. We found that PRDM2 showed a synergy inhibition with BRC on PRL secretion and MMQ cell viability (Figure 6).

\section{Low PRDM2 mRNA levels is associated with tumor recurrence in prolactinomas}

Between 2008 and 2013, 24 patients with prolactinomas were enrolled in our study. Follow-up periods ranged from 6 months to 5 years (mean 4.0 years). The median expression level was used as the cutoff. Low PRDM2 mRNA levels were defined as values below the 50th percentile of the 12 patients; values at or above the 50th percentile were classified as high levels. We then asked whether low PRDM2 mRNA levels in prolactinomas were associated with any clinical parameters (Table 2.) (Chi squared tests). There was no significant correlation

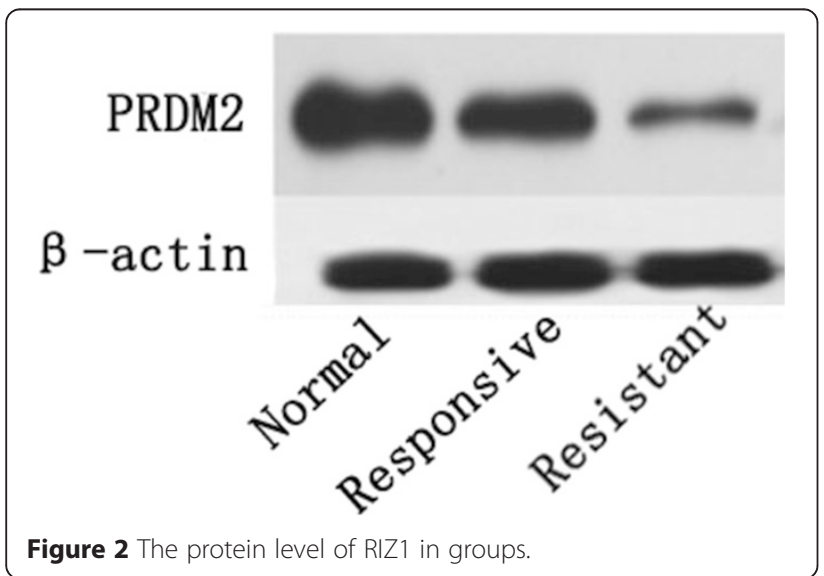

between PRDM2 mRNA levels and age, gender, tumor size or PRL serum levels. However, low PRDM2 mRNA levels were more frequently observed in recurrent tumors $(p=0.011)$ and BRC-resistant tumors $(p=0.037)$. Recurrence was defined as the discovery of an elevated PRL level at any time in the postoperative surveillance period after an initial remission [1]. Furthermore, binary multivariate regression revealed that low levels of PRDM2 mRNA were independently associated with tumor recurrence (odd ratio [OR] 0.065, 95\% confidence interval [CI]: $0.05-0.832, \mathrm{p}=0.036)$.

\section{Discussion}

Previous studies showed that some DA-resistant prolactinomas have reduced dopamine $\mathrm{d} 2$ receptor density using different methods $[15,16]$. The proportion of D2Rencoding mRNA corresponding to the D2S isoform was lower in resistant prolactinomas than in responsive tumors have demonstrated by other studies $[17,18]$. Wholeexome sequencing identified sequence variants associated with 10 genes, not previously implicated in DA-resistant prolactinomas. In addition, our analysis identified somatic variants in established oncogenes, tumor suppressor genes and genes associated with DNA repair and protein metabolic processes.

In the present study, PRDM2 mRNA levels were approximately five-fold lower in resistant prolactinomas than in the responsive tumors $(\mathrm{p}<0.05)$. PRDM2 protein levels were significantly lower in resistant prolactinomas than in the responsive tumors $(\mathrm{p}<0.05)$. In addition, Confocal images showed that the number of PRDM2positive puncta in BRC-resistant prolactinomas was lower than that of the normal pituitary and sensitive prolactinomas $(\mathrm{p}<0.05)$. We found that PRDM2 showed a synergy inhibition with BRC on PRL secretion and MMQ cell viability. Further analysis of our data confirmed that low levels of PRDM2 were more frequently observed in recurrent tumors. Furthermore, binary multivariate regression analysis revealed that low PRDM2 expression level was independently associated with prolactinoma recurrence (OR 0.065; 95\% CI: 0.05-0.832; $\mathrm{p}=0.036$ ).

Pellegrini et al. [15] in 1989 found that D2R levels were lower in dopamine resistant prolactinomas. And then, the same group showed also a lower expression of pituitary specific PIT1 (POU1F1) transcription factor in dopamine resistant prolactinomas [18]. Raverot et al. [19] found already seven genes mRNA level variation, notably PPTG and CCNB1, were associated with tumor recurrence or progression. Delgrange et al. [20] reported that resistant prolactinomas tend to be more invasive and to recur more often than responsive tumors. Furthermore, recurrent prolactinomas were more likely to be resistant to the drug therapy. Some authors $[3,18,21]$ reported that resistant prolactinomas tend to be more 


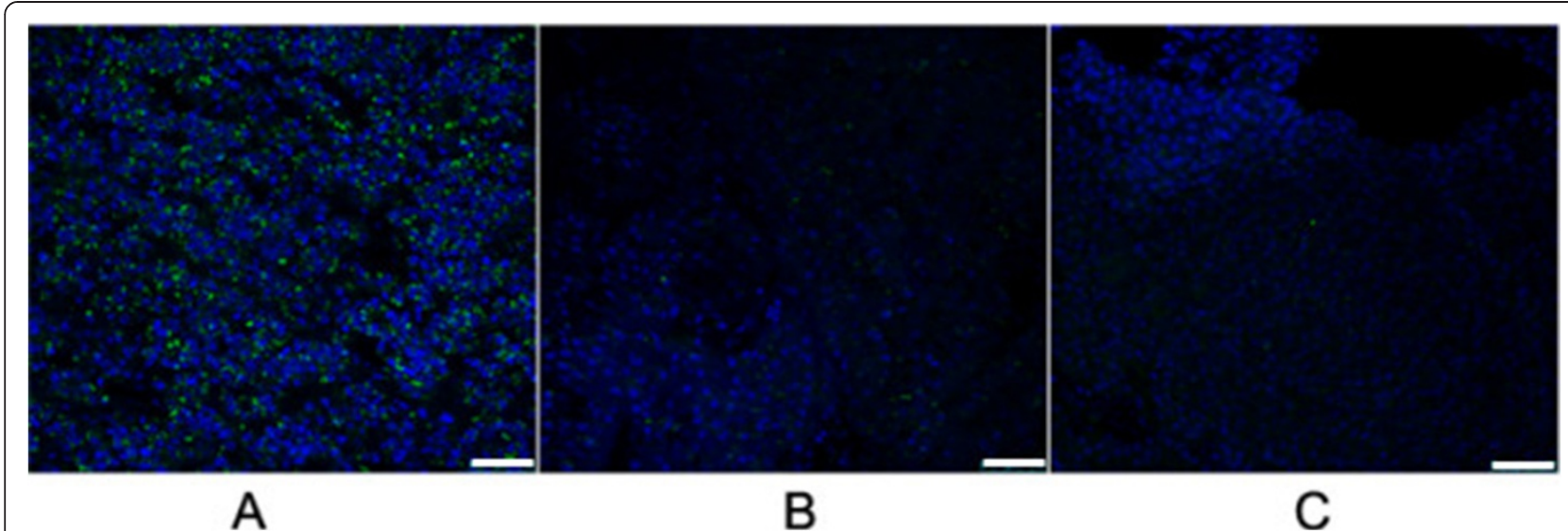

Figure 3 The expression level of RIZ1 in different groups through Confocal. A: Normal. B: BRC-Responsive prolactinomas; C BRC-Resistant prolactinomas. Green: RIZ1 Blue: DAPI. Bar: $50 \mu \mathrm{M}$

invasive and recur more often than responsive tumors. Furthermore, recurrent prolactinomas are more likely to be resistant to drug therapy.

Buyse et al. first found PRDM2 by retinoblastoma (Rb) probes in 1995, while performing a functional screen for $\mathrm{Rb}$, and observed that it was able to interact with $\mathrm{Rb}$ [22]. Fluorescent in situ hybridization showed that the PRDM2 gene is located on human chromosome $1 \mathrm{p} 36$. There are two variants of PRDM2, RIZ1 and RIZ2, according to two alternative initial locations $[23,24]$. The sequences of RIZ1 and RIZ2 are same, except the presence of a PR domain in RIZ1. Generally, RIZ1 is refers to PRDM2 protein. The PR domain in RIZ1 is named after the PRDI-BF1-RIZ1 region and contains about 100 amino acids. The role of the structure is to stabilize

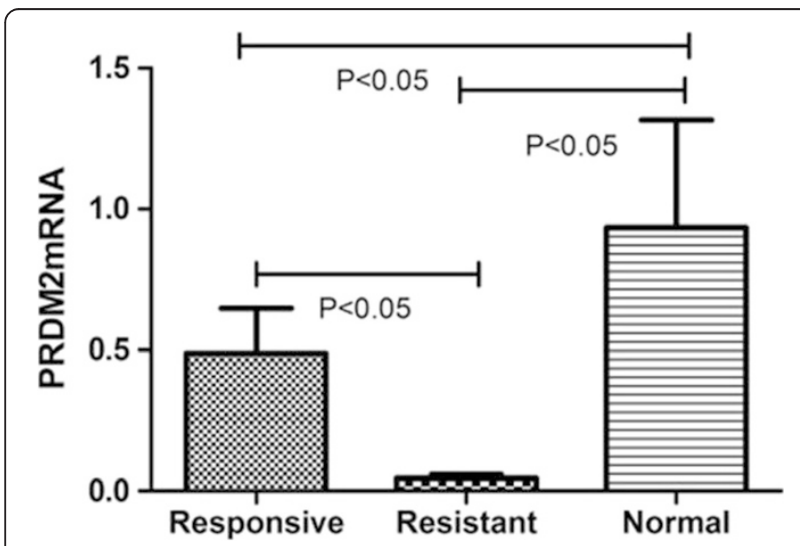

Figure 4 Mean PRDM2 mRNA levels in BRC-responsive and BRC resistant prolactinomas and in normal pituitary. PRDM2 expression was measured by RT-qPCR in 6 BRC-responsive prolactinomas, 6 BRC resistant prolactinomas and 6 normal pituitary glands. Horizontal lines above the bars represent standard deviations (statistical method: one-way analyses of variance) chromosomal structures and, therefore, mediate gene expression [25]. The presence or absence of a PR domain results in the differential expression of proteins at an early stage of tumorigenesis, which provides a mechanism for tumor initiation [26]. Some reports have demonstrated that RIZ1 is able to inhibit tumor development and is thought to be a tumor suppressor gene $[14,27,28]$. Furthermore, because RIZ1 closely interacts with $\mathrm{Rb}$, which induces the arrest of tumor cells in the G2/M phase resulting to cell death, up-expression of RIZ1 may lead to arrest of tumor [26].

As a new tumor suppressor, PRDM2 has been analyzed in a few reports, which have attempted to explain the reasons the gene is inactivated in cancer cells. Genetic and epigenetic changes are thought to be responsible [29,30]. According to a genetic perspective, PRDM2 may be down-regulated by chromosomal instability and microsatellite instability, as well as frame-shift mutations, point mutations and heterozygote deficiency $[14,29,31]$. From an epigenetic perspective, the deactivation of PRDM2 may occur due to promoter methylation and histone acetylation [32]. Changes to chromosome 1p36, on which PRDM2 is located, are also associated with numerous types of cancer, including breast cancer, ovarian cancer, liver cancer, colorectal cancer, chronic myeloid leukemia, melanoma, chromaffin tumor and neuroblastoma [29]. In all these tumor types, the tumor tissue samples and cancer cell lines displayed low expression levels or deficiency of PRDM2. In our study, we found the low PRDM2 level in BRC-resistance prolactinomas because of inser mutation (chr1:14106398, TCC). Overexpression of PRDM2 in MMQ cells could up-regulate the D2DR lelvel, and we speculates that PRDM2 is potential synergy inhibition with BRC through the PRL secretion and cell viability tests of MMQ cells. 

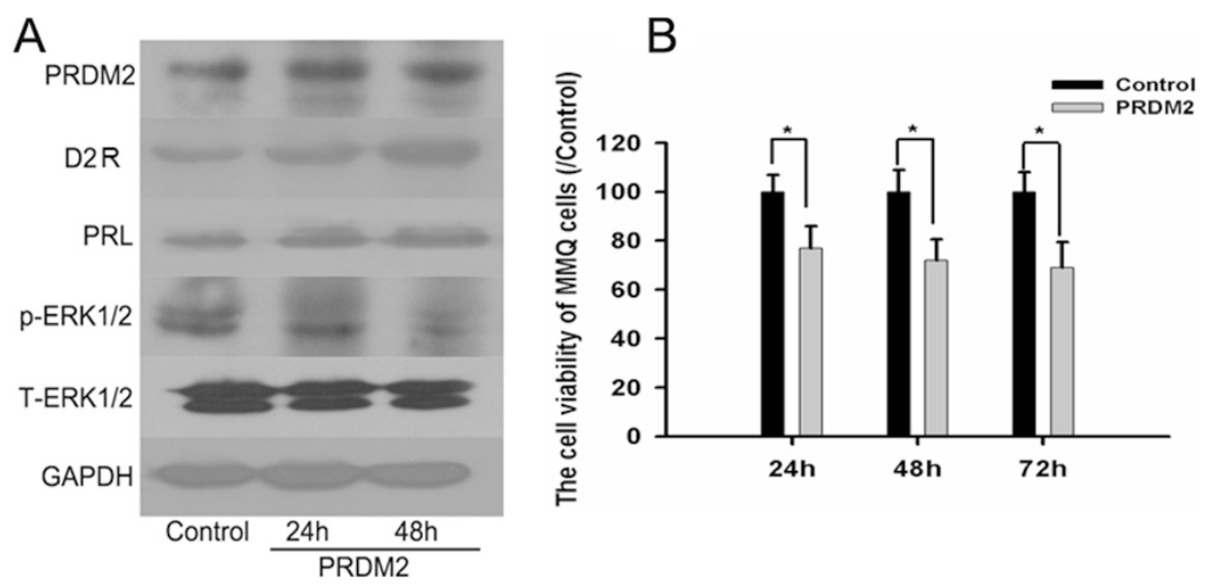

Figure 5 Overexpression PRDM2 could increase the D2R level and inhibit the cell proliferatin of MMQ cells. A: Overexpression PRDM2 could increase the D2R level and reduce the phosphorylation of ERK1/2 in MMQ cells. B: Overexpression of PRDM2 could inhibit the cell proliferation of MMQ cells. $n=3 *$ compared to Control group.

BRC inhibits DNA synthesis and delays the cell cycle [33]. The BRC-resistance of prolactinomas is associated with several processes including drug efflux by transporters, inactivation by detoxifying enzymes, altered expression of pro-/anti-apoptotic proteins or tumor suppressors, and increased activity of DNA repair mechanisms [34,35]. In many cases, only single base pair changes are required to activate, silence, or functionally alter critical genes (e.g., proto-oncogenes, tumor suppressor genes) in a cell type-, differentiation stage-, and carcinogen-specific manner. The DNA repair machinery can be seen as a "caretaker" [36] in charge of preserving the integrity and stability of the genome. Specific base substitutions (point variants) in genomic DNA may be caused by endogenous and exogenous mechanisms and DNA-reactive agents. In the present study, 10 variants were associated with DNA repair or DNA metabolic processes, including PRDM2, PRG4, MUC4, DSPP,
DPCR1, etc. Frame-shift mutations of the PRDM2 gene are also common in microsatellite instability-positive tumors and truncate a PR-interacting domain [23].

\section{Conclusion}

In summary, our results suggest that low levels of PRDM2 may contribute to promote drug resistance and tumor recurrence of prolactinomas in an as yet unknown manner. Further work will be required to extend the potential links between PRDM2, drug resistance and tumor recurrence. Our results demonstrate that whole-exome sequencing will be particularly valuable for gene discovery under conditions in which mapping has been confounded by locus heterogeneity and uncertainty about the boundaries of diagnostic classification, pointing to a bright future for its broad application to medicine.

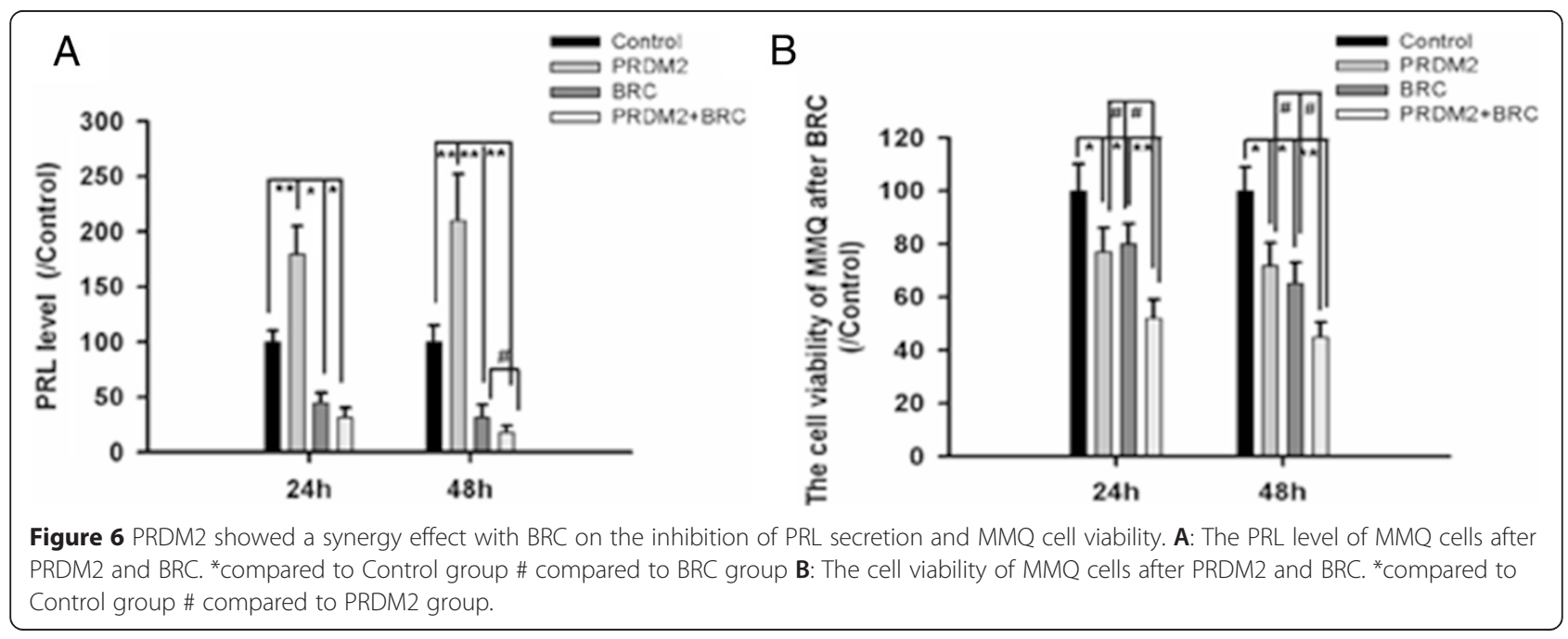




\section{Additional file}

Additional file 1: Table S1. The original data of 10 genes with mutations in prolactinomas.

\section{Abbreviations \\ MTT: 3-(4,5-dimethylthiazol-2-yl)-2,5-diphenyl tetrazolium; Cl: Confidence interval; DAPI: 4',6-diamidino-2-phenylindole; DA: Dopamine agonists; BRC: Bromocriptine; DNA: Deoxyribonucleic acid; D2DR: Dopamine receptor D2; NCBI: National Center for Biotechnology Information; PRL: Prolactin; RT-qPCR: Real-time reverse-transcription PCR; RNA: Ribonucleic acid; SNP: Single-nucleotide polymorphism; TNE: Tris sodium chloride EDTA buffer; PVDF: Polyvinylidene fluoride; RIZ: Retinoblastoma interacting zinc-finger protein}

\section{Competing interests}

The authors declare that they have no competing interests.

\section{Authors' contributions}

HG made substantial contributions to conception and design. FW, FJ and CZ $\mathrm{L}$ carried out the molecular genetic studies and $\mathrm{XL} L$ and JW B carried out the immunoassays and LC participated in the sequence alignment and collected the clinical data SB G involved in drafting the manuscript LC H participated in the design of the study $Y Z Z Z$ conceived of the study, and participated in its design and coordination and helped to draft the manuscript. All authors read and approved the final manuscript.

\section{Acknowledgments}

This work was supported by the National Natural Science Foundation of China (81272522, 81072075), China National Clinical Research Center for Neurological Diseases (2013BAI09B03), the Key Program of the Natural Science Foundation of Beijing (7121004), the Beijing Natural Science Foundation (7144198), and the open fund of neurobiology of Capital Medical University.

\section{Author details}

${ }^{1}$ Beijing Neurosurgical Institute, Capital Medical University, Beijing, China. ${ }^{2}$ Department of Neurosurgery, Provincial Hospital Affiliated to Anhui Medical University, Hefei, Anhui Province, China. ${ }^{3}$ Neurosurgical Department, The Affiliated Hospital of Medical College, Qingdao University, China; and Capital Medical University, Beijing, China. ${ }^{4}$ Neurosurgical Department of Beijing Tiantan Hospital, Beijing, China. ${ }^{5}$ Tsinghua University, Beijing, China.

\section{Received: 8 July 2014 Accepted: 25 March 2015}

\section{Published online: 12 April 2015}

\section{References}

1. Gillam MP, Molitch ME, Lombardi G, Colao A. Advances in the treatment of prolactinomas. Endocr Rev. 2006;27(5):485-534.

2. Iyer $\mathrm{P}$, Molitch ME. Positive prolactin response to bromocriptine in 2 patients with cabergoline-resistant prolactinomas. Endocr Pract. 2011;17(3):e55-8

3. Wang F, Gao H, Li C, Bai J, Lu R, Cao L, et al. Low levels of PRB3 mRNA are associated with dopamine-agonist resistance and tumor recurrence in prolactinomas. J Neurooncol. 2014;116(1):83-8.

4. Colao A, Savastano S. Medical treatment of prolactinomas. Nat Rev Endocrinol. 2011;7(5):267-78.

5. Vroonen L, Daly A, Beckers A. Management of prolactinoma. Rev Med Suisse. 2013:9(395):1522-6.

6. Kumar KV, Prusty P. Resistant prolactinoma: Is it monoclonal or polyclonal? Indian J Endocrinol Metab. 2013;17 Suppl 1:S139-41.

7. Molitch ME. Management of medically refractory prolactinoma. J Neurooncol. 2014;117(3):421-8.

8. Osamura RY, Egashira N, Miyai S, Yamazaki M, Takekoshi S, Sanno N, et al. Molecular pathology of the pituitary. Development and functional differentiation of pituitary adenomas. Front Horm Res. 2004:32:20-33.

9. Gao H, Yang W, Qi Z, Lu L, Duan C, Zhao C, et al. DJ-1 protects dopaminergic neurons against rotenone-induced apoptosis by enhancing ERK-dependent mitophagy. J Mol Biol. 2012;423(2):232-48.
10. Barbieri CE, Baca SC, Lawrence MS, Demichelis F, Blattner M, Theurillat JP, et al. Exome sequencing identifies recurrent SPOP, FOXA1 and MED12 mutations in prostate cancer. Nat Genet. 2012;44(6):685-9.

11. Lloyd RV. Molecular pathology of pituitary adenomas. J Neurooncol. 2001;54(2):111-9.

12. lacobuzio-Donahue CA. Epigenetic changes in cancer. Annu Rev Pathol. 2009;4:229-49.

13. Raverot G, Wierinckx A, Dantony E, Auger C, Chapas G, Villeneuve L, et al. HYPOPRONOS. Prognostic factors in prolactin pituitary tumors: clinical, histological, and molecular data from a series of 94 patients with a long postoperative follow-up. J Clin Endocrinol Metab. 2010;95(4):1708-16.

14. Congdon LM, Sims JK, Tuzon CT, Rice JC. The PR-Set7 binding domain of Riz1 is required for the H4K20me1-H3K9me1 trans-tail 'histone code' and Riz1 tumor suppressor function. Nucleic Acids Res. 2014;42(6):3580-9.

15. Pellegrini PI, Rasolonjanahary R, Gunz G, Bertrand P, Delivet S, Jedynak CP, et al. Resistance to bromocriptine in prolactinomas. J Clin Endocrinol Metab. 1989;69(3):500-9.

16. Kukstas LA, Domec C, Bascles L, Bonnet J, Verrier D, Israel JM, et al. Different expression of the two dopaminergic D2 receptors, D2415 and D2444, in two types of lactotroph each characterised by their response to dopamine, and modification of expression by sex steroids. Endocrinology. 1991;129(2):1101-3.

17. Caccavelli L, Feron F, Morange I, Rouer E, Benarous R, Dewailly D, et al. Decreased expression of the two D2 dopamine receptor isoforms in bromocriptine-resistant prolactinomas. Neuroendocrinology. 1994;60(3):314-22.

18. Wu ZB, Zheng WM, Su ZP, Chen Y, Wu JS, Wang CD, et al. Expression of D2RmRNA isoforms and ERmRNA isoforms in prolactinomas: correlation with the response to bromocriptine and with tumor biological behavior J Neurooncol. 2010;99(1):25-32.

19. Pellegrini-Bouiller I, Morange-Ramos I, Barlier A, Gunz G, Figarella-Branger D, Cortet-Rudelli C, et al. Pit-1 gene expression in human lactotroph and somatotroph pituitary adenomas is correlated to D2 receptor gene expression. J Clin Endocrinol Metab. 1996;81(9):3390-6.

20. Delgrange E, Sassolas G, Perrin G, Jan M, Trouillas J. Clinical and histological correlations in prolactinomas, with special reference to bromocriptine resistance. Acta Neurochir (Wien). 2005:147(7):751-8.

21. Newey PJ, Nesbit MA, Rimmer AJ, Head RA, Gorvin CM, Attar M, et al. Whole-exome sequencing studies of nonfunctioning pituitary adenomas. J Clin Endocrinol Metab. 2013;98(4):E796-800.

22. Buyse IM, Shao G, Huang S. The retinoblastoma protein binds to RIZ, a zinc-finger protein that shares an epitope with the adenovirus E1A protein. Proc Natl Acad Sci U S A. 1995:92(10):4467-71.

23. Ng WT, Choi CW, Chan SH, Yau TK, Lee AW. Familial nasopharyngeal carcinoma in Hong Kong: epidemiology and implication in screening. Fam Cancer. 2009:8(2):103-8.

24. Liu ZY, Wang JY, Liu HH, Ma XM, Wang CL, Zhang XP, et al. Retinoblastoma protein-interacting zinc-finger gene 1 (RIZ1) dysregulation in human malignant meningiomas. Oncogene. 2013;32(10):1216-22.

25. Szende B, Tyihak E. Effect of formaldehyde on cell proliferation and death. Cell Biol Int. 2010;34(12):1273-82.

26. Overmeer RM, Louwers JA, Meijer CJ, van Kemenade FJ, Hesselink AT, Daalmeijer NF, et al. Combined CADM1 and MAL promoter methylation analysis to detect (pre-)malignant cervical lesions in high-risk HPV-positive women. Int J Cancer. 2011;129(9):2218-25.

27. Dong SW, Zhang P, Liu YM, Cui YT, Wang S, Liang SJ, et al. Study on RIZ gene promoter methylation status in human esophageal squamous cell carcinoma. World J Gastroenterol. 2012;18(6):576-82.

28. Dong SW, Li D, Xu C, Sun P, Wang YG, Zhang P. Alteration in gene expression profile and oncogenicity of esophageal squamous cell carcinoma by RIZ1 upregulation. World J Gastroenterol. 2013;19(37):6170-7.

29. Sun W, Geyer CR, Yang J. Cloning, expression, purification and crystallization of the PR domain of human retinoblastoma protein-binding zinc finger protein 1 (RIZ1). Int J Mol Sci. 2008;9(6):943-50

30. Zhao F, Chen Y, Zeng LL, Li R, Zeng R, Wen L, et al. Effects of triptolide on RIZ1 expression, proliferation, and apoptosis in multiple myeloma U266 cells. Acta Pharmacol Sin. 2010:31(6):733-40.

31. Chadwick RB, Jiang GL, Bennington GA, Yuan B, Johnson CK, Stevens MW, et al. Candidate tumor suppressor RIZ is frequently involved in colorectal carcinogenesis. Proc Natl Acad Sci U S A. 2000;97(6):2662-7.

32. Xu RR, Xuan LN, Wang Y. Methylation status of RIZ1 gene promoter in myelodysplastic syndrome. Zhonghua Xue Ye Xue Za Zhi. 2012;33(9):774-5. 
33. Prysor-Jones RA, Jenkins JS. Effect of bromocriptine on DNA synthesis, growth and hormone secretion of spontaneous pituitary tumours in the rat.". J Endocrinol. 1981;88(3):463-9.

34. LaPensee EW, Schwemberger SJ, LaPensee CR, el Bahassi M, Afton SE, Ben-Jonathan N. Prolactin confers resistance against cisplatin in breast cancer cells by activating glutathione-S-transferase. Carcinogenesis. 2009:30(8):1298-304.

35. Murakami M, Mizutani A, Asano S, Katakami H, Ozawa Y, Yamazaki K, et al. A mechanism of acquiring temozolomide resistance during transformation of atypical prolactinoma into prolactin-producing pituitary carcinoma: case report. Neurosurgery. 2011;68(6):E1761-7.

36. Hickson ID. RecQ helicases: caretakers of the genome. Nat Rev Cancer. 2003;3(3):169-78.

\section{Submit your next manuscript to BioMed Central} and take full advantage of:

- Convenient online submission

- Thorough peer review

- No space constraints or color figure charges

- Immediate publication on acceptance

- Inclusion in PubMed, CAS, Scopus and Google Scholar

- Research which is freely available for redistribution 